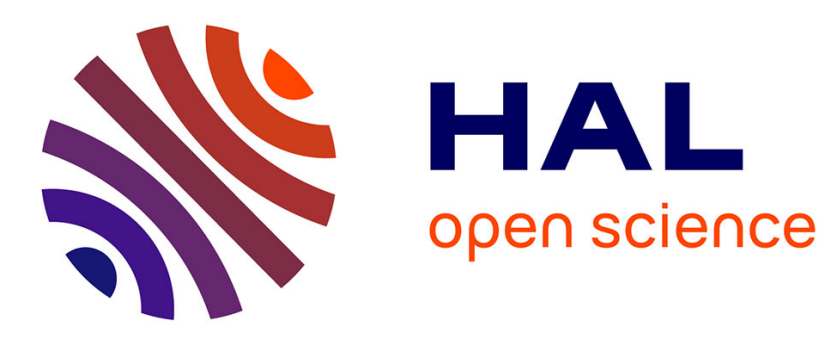

\title{
High spatial resolution solar atlas in Provence-Alpes-Cote d'Azur
}

Philippe Blanc, Bella Espinar, Benoît Gschwind, Lionel Ménard, Claire Thomas, Lucien Wald

\section{- To cite this version:}

Philippe Blanc, Bella Espinar, Benoît Gschwind, Lionel Ménard, Claire Thomas, et al.. High spatial resolution solar atlas in Provence-Alpes-Cote d'Azur. ISES Solar World Congress 2011, Aug 2011, Kassel, Germany. paper \#34552. hal-00630734

\section{HAL Id: hal-00630734}

https://hal-mines-paristech.archives-ouvertes.fr/hal-00630734

Submitted on 10 Oct 2011

HAL is a multi-disciplinary open access archive for the deposit and dissemination of scientific research documents, whether they are published or not. The documents may come from teaching and research institutions in France or abroad, or from public or private research centers.
L'archive ouverte pluridisciplinaire HAL, est destinée au dépôt et à la diffusion de documents scientifiques de niveau recherche, publiés ou non, émanant des établissements d'enseignement et de recherche français ou étrangers, des laboratoires publics ou privés. 


\title{
HIGH SPATIAL RESOLUTION SOLAR ATLAS IN PROVENCE-ALPES-CÔTE D'AZUR
}

\author{
Philippe Blanc ${ }^{1}$, Bella Espinar', Benoit Gschwind ${ }^{1}$, Lionel Menard ${ }^{1}$, Claire Thomas ${ }^{2}$ and Lucien Wald ${ }^{1}$ \\ ${ }^{1}$ MINES ParisTech / ARMINES, Centre for Energy and Processes, Sophia Antipolis (France) \\ ${ }^{2}$ TRANSVALOR, Sophia Antipolis (France)
}

\section{Introduction}

Most existing solar atlases cover a continent or a country with a spatial resolution coherent with such visualization. These atlases generally depict yearly sum of Global Horizontal Irradiation (GHI). Thus they give a good idea of the large scale solar trends, which are particularly suited for an application of identification of wide areas of high solar potential. However, these large scale atlases of yearly GHI data are not appropriate for the local estimation of solar systems, such as the precise estimation of the electrical production from PV plants, Concentrated Photovoltaic CPV technologies and from Concentrated Solar Power (CSP) systems.

Such applications require a finer spatial resolution, as well as the knowledge of the other solar components (direct or Beam Normal Irradiation, BNI, and Diffuse Horizontal Irradiation, DHI) in conjunction with their temporal evolution through the seasons of the year. This communication introduces the Solar Atlas over the French region of Provence-Alpes-Côte d'Azur (PACA) which aims at fulfilling these requirements. The PACA Solar Atlas was launched in January 2009 and has been finalized in December 2010. The purpose is to create $250 \mathrm{~m}$ resolution solar maps for different plane orientations: horizontal, tilted and normal to sun rays. The atlas will account for the temporal intra and inter-annual variations on a monthly basis of the different components of the incident sun radiation.

It exploits the advantages of both the satellite-based solar radiation databases and the in situ ground station measurements. Satellite-based datasets provide homogeneous information over a large area, but with a spatial resolution limited to the one of the satellite image. Networks of ground stations generally offer very precise information at the location of the stations but the geographical distribution of this information is scarce and heterogeneous. The PACA Solar Atlas combines both sources of radiation by calibrating the satellite-based solar radiation database HelioClim-3 using the available ground stations.

The enhancement of the spatial resolution from the approx. $5 \mathrm{~km}$ of HelioClim-3 to the announced 250 meters of the atlas has been achieved using the high resolution Digital Elevation Model (DEM) named Shuttle Radar Topography Mission (SRTM) (Farr et al., 2007). This orographic information is exploited to modulate the intra-pixel radiation due to the shadowing effect of the horizon and to introduce the variation of the atmospheric layer thickness above a given geographical location.

Mines ParisTech, located in Sophia Antipolis in the French Riviera, realized the Solar Atlas project thanks to the support and funding of local and regional organizations and councils: ADEME PACA, the PACA region, the council of the Department "Alpes Maritimes", as well as CAPENERGIES, a competitive cluster for Energy in PACA. One reason which motivated this investment is the weakness of the electrical network in the French department of "Alpes Maritimes". Indeed, only one double line provides the electricity from the national electricity network to the whole department, due to the fact that the PACA region is located at the end of one of the distribution lines. This drastic constraint led several times to a shortage of electricity during a few hours, for instance like a freezing morning in winter 2009. Therefore, regional organizations and councils are interested in promoting alternative electricity generation and associated tools.

This orientation in the energy policy of our region is coherent with the large increase in the number of PV installations, and with the growing interest of the population and companies for the renewable energies. The PACA Solar Atlas is designed for a wide audience by providing an access-free tool for all to discover or exploit the solar potential of the region. With its online map and time series services, it is an interesting 
trade-off between an educative and a fully expert tool to access the solar radiation information. It is suitable for sizing large and small individual solar systems (small PV system, solar water heating systems, etc). Accurate and well-presented solar maps are concrete and instructive for everybody (e.g. education) to promote solar energy.

\section{Data and calibration}

Since February 2004, the Heliosat-2 algorithm (Rigollier et al. 2004) applied to Meteosat Second Generation (MSG) SEVIRI images has been used to update, every night, the solar resource database HelioClim-3 (HC3). This database covers Europe, Africa, the Mediterranean Basin, the Atlantic Ocean and part of the Indian Ocean with a spatial resolution of approximately $5 \mathrm{~km}$ (see Fig. 1) at a fifteen minutes temporal resolution. The MSG data are received in real time from Eumetsat and processed overnight.

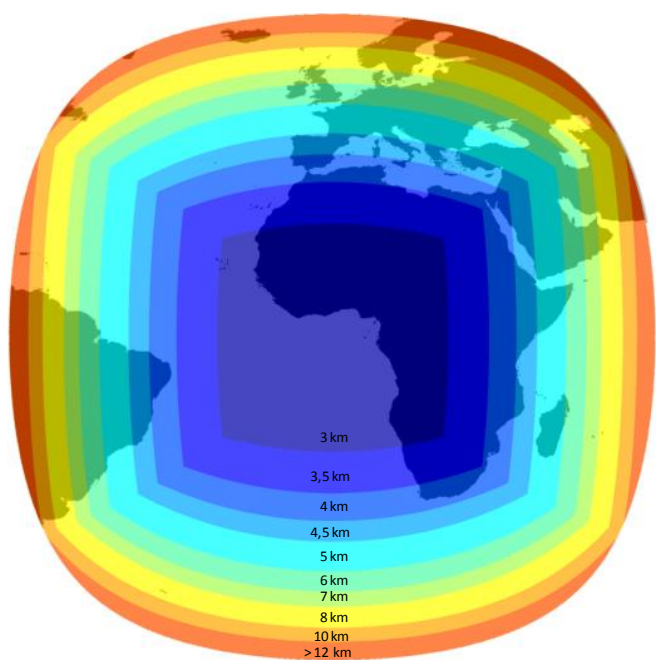

Fig. 1: Spatial coverage and resolution of HelioClim3 solar resource database

The ground stations used for the HC3 calibration over the PACA region are displayed on Fig. 2. They consist in twenty-nine ground stations from Météo France (MF, blue markers) and three Rotating Shadowband Pyranometers (RSP, red squares) dedicated to the project. The blue triangles identify the MF stations located in mountainous areas, i.e. the MF stations affected by the shadowing effect of the horizon. To make the HC3 data and the ground station measurements comparable, mountainous ground station data have been specifically processed to take into account the horizon effect in the calibration procedure. 


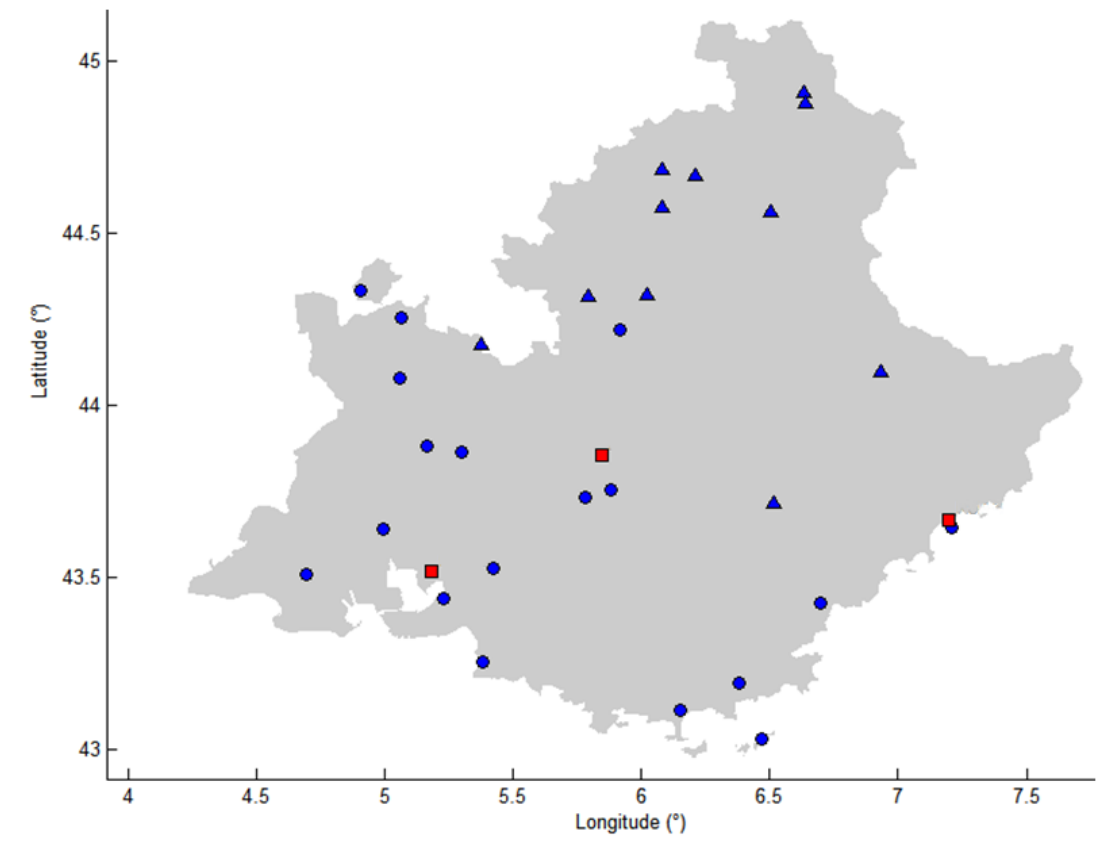

Fig. 2: Location in the PACA region of the twenty-nine meteorological stations from Météo France (blue circles and triangles) and of the three RSP stations (in red). Blue triangles correspond to meteorological stations in mountainous areas.

The three RSP stations were expressly rent for the duration of the project, to the company CSP Service, a spin-off of the German national centre for aeronautics and space (DLR). They provide global and diffuse irradiation on the horizontal plane with a 10 minutes sampling, as well as the ambient temperature and the relative humidity. The RSP systems return accurate values and are very robust with respect to dust and misalignments (Geuder et al. 2003).

Most stations of the MF network only provide GHI. In the zone of interest, only the station of Carpentras, which also belongs to the high quality ground station network Baseline Surface Radiation Network (BSRN, www.bsrn.awi.de) network, also returns DHI and BNI values (Ohmura et al. 1998). The dedicated RSP stations deliver complete GHI, DHI and BNI information; please note that this last is computed and not directly measured like the other two components.

The calibration was performed on the data reduced to a daily basis. This avoids the need to take into account the numerous missing hourly values in the MF data, as well as the potential time shift which we noticed in the past. These imperfections are smoothed out with the daily time step. Only full day of data have been considered in the evaluation and calibration protocols.

The data quality control described in Geiger et al. (2002) and Long and Shi (2006) has been applied to the data from all the stations. Also an analysis of the distribution of missing data in the period from 2004 to 2010 has been done in order to exclude stations that do not have in this period a sufficient number of daily observations for statistical studies. After these procedures, twenty MF stations were deemed of satisfying quality, and were used for the project with the three RSP stations.

First of all, a method for the parametric correction of the HC3 data was determined. The parameters of the calibration have been estimated at each exact location of the stations. Then, next step consisted in propagating these limited number of discrete correction parameters to whole area of the PACA region (Baillargeon 2005, Wahba et al. 1990). After several tests, the thin plate interpolation method (Xia et al. 2000) turned out to return the most appropriate maps of correction parameters to be directly applied on the HC3 irradiation maps. 


\section{Horizon}

The spatial resolution enhancement is obtained exploiting two HC3 intra-pixel effects induced by the relief, the optical depth variations of the atmosphere and the shadowing effect from the far horizon (Dozier and Frew 1990, Pavlis et al. 2006.). The DEM used for this spatial resolution improvement is SRTM (Farr et al. 2007), with $100 \mathrm{~m}$ of spatial resolution and a localization accuracy better than $10 \mathrm{~m}$.

Abdel Wahab et al. (2008) show that the irradiation values can be modulated by the optical depth variations of the atmosphere. For instance, at the summit of a mountain, the atmospheric thickness is smaller than at the bottom of a valley. As the atmosphere thins, more radiation reaches the ground. Consequently, the intra pixel radiation value can be multiplied by a coefficient which is a function of the altitude.

But the main influence of orography on the different radiation components is the shadowing effect produced by the horizon at a given geographical location. Fig. 3 depicts an example of the orographic horizon (black area) and the different trajectories of the sun along the year (yellow lines) in clear sky conditions. In the first and last hours of the days, the sun is occulted by the surrounding hills and mountains.

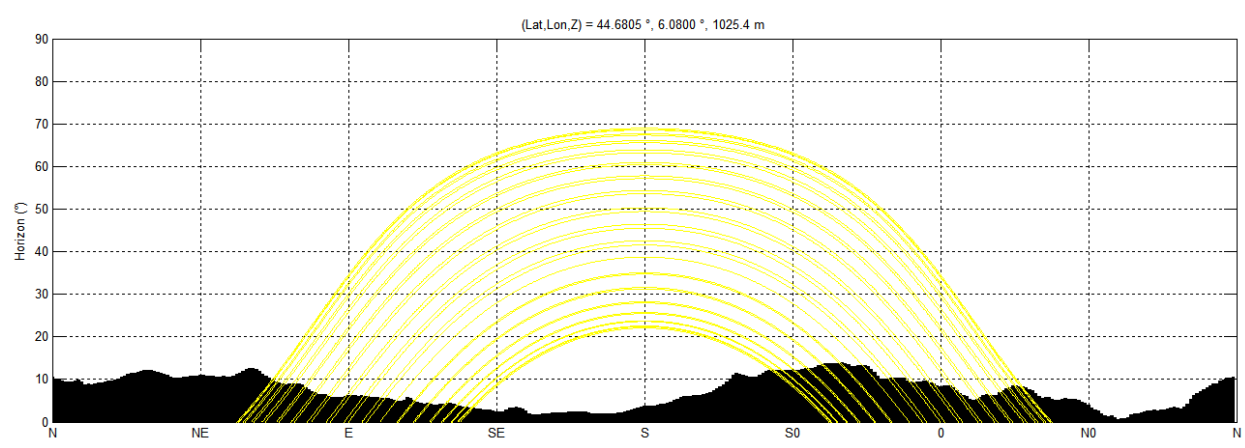

Fig. 3: Example of horizon (black area) computed from the DEM SRTM at the location $\left(44.6805^{\circ} \mathrm{N}, 6^{\circ} 08^{\circ} \mathrm{E}\right)$. The daily trajectories of the sun are represented in yellow (three trajectories per month along the year). The $\mathbf{x}$ axis is the azimuth orientation, beginning from the North. The $y$ axis is the elevation angle, in degrees.

To achieve this purpose, the different components of the intra-pixel radiation have been modulated using the models proposed by Ruiz-Arias (2009). Beside an isotropic model for the DHI and the "on/off" behaviour of the Beam Horizontal Irradiation (BHI) component when the sun is masked behind the horizon, this publication has investigated the impact of the circumsolar ring of the sun during daytime into the diffuse component.

\section{Results}

The methodology for the atlas creation can be summarized into the following steps:

- Calibration of HC3 with the $20 \mathrm{MF}$ ground stations which passed the quality check procedure and the 3 RSP stations,

- Improvement of spatial resolution of HC3 by the use of the SRTM model,

- Decomposition of this corrected GHI into BNI and DHI (based on the algorithms of ESRA 2000, Ruiz-Arias et al. 2010, Perez et al. 1990 and 1992).

The results are maps of the annual and monthly values for the three solar irradiation components with a spatial resolution of $250 \mathrm{~m}$ over the PACA region. These maps are available for horizontal incidence of the solar components as well as for incidence on normal and tilted planes. Fig. 4 and 5 are two examples of yearly sums of GHI and BNI respectively. 


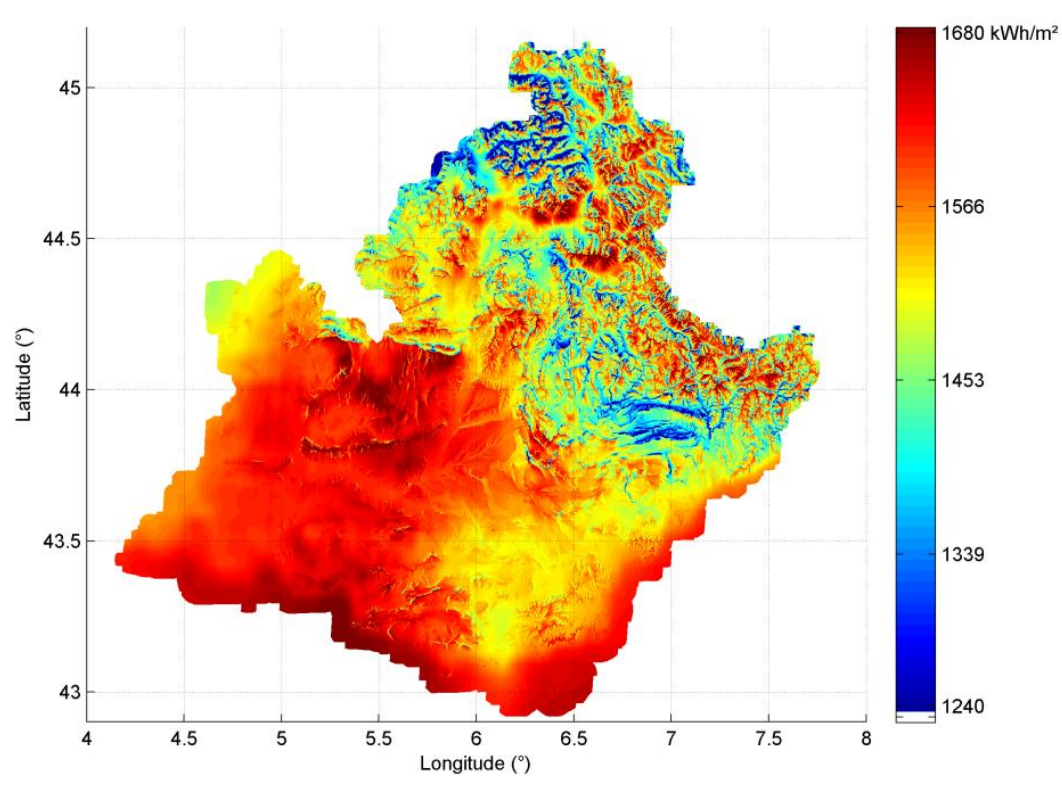

Fig. 4: Map of yearly average sum of global horizontal irradiation $\left(\mathrm{GHI}, \mathrm{kWh} / \mathrm{m}^{2}\right)$. The period for the average is from 2004 to 2010.

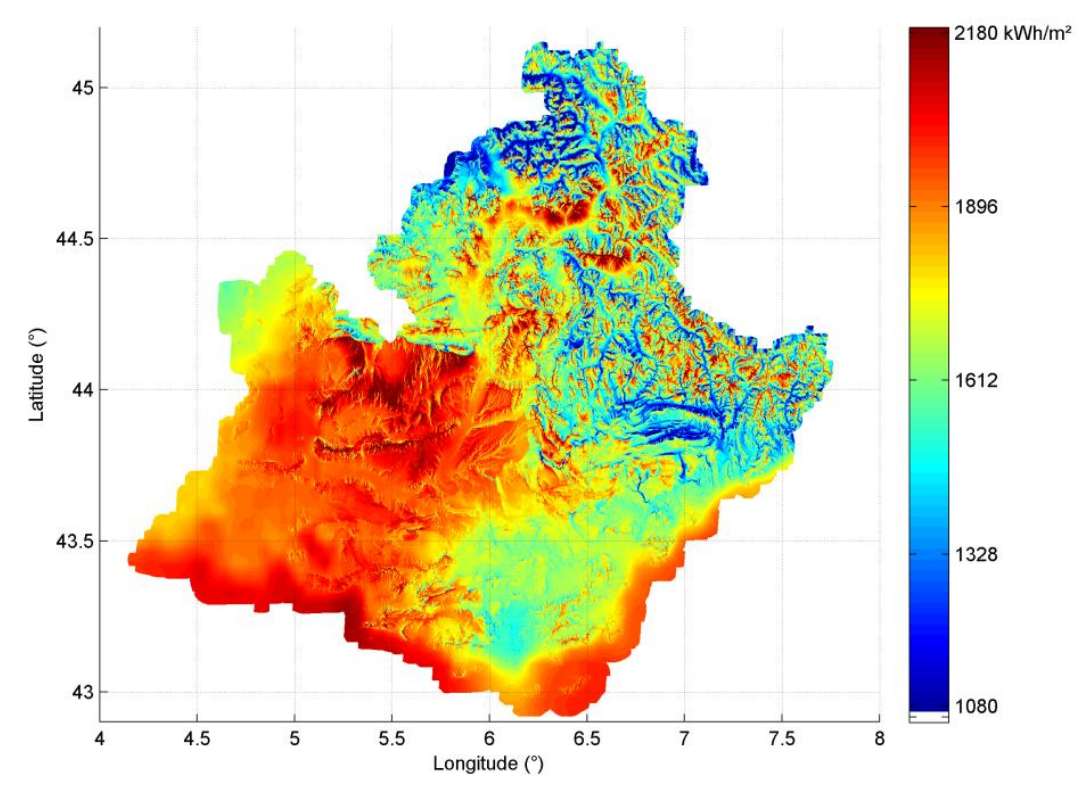

Fig 5: Map of yearly average sum of direct normal irradiation $\left(\mathrm{BNI}, \mathrm{kWh} / \mathrm{m}^{2}\right)$. The period for the average is from 2004 to 2010.

\section{Validation and estimation of the uncertainty of the solar atlas}

The uncertainties of the monthly sums of GHI provided by the solar atlas have been assessed in two ways:

- The statistical analysis, before and after the calibration procedure, of the residual discrepancies of the estimation of the monthly sums of GHI with respect to the twenty MF meteorological ground stations. In addition, as all these stations have been used for the calibration, a statistical analysis based on the LeaveOne-Out Cross-Validation (LOOCV) approach (Arlot and Celisse, 2010) was also made.

- The statistical analysis, before and after the calibration procedure, of the residual discrepancies of the estimation of the monthly sums of GHI with respect the three RSP stations considered as test stations because they have not been used for the calibration.

The statistical measures of the discrepancy of a time series of irradiation with respect to a reference are the mean bias error (MBE), the mean absolute error (MAE), the root mean square error (RMSE) and the 
correlation coefficient (CC). Apart from the last one, these measures are relative to the mean value of the reference time series (MREF) and are expressed in percentage. NDATA corresponds to the number of data that have been used for the comparison.

Fig. 6 represents graphically these statistical results before any calibration or orographic effect correction of $\mathrm{HC} 3$ at all the ground stations locations over the PACA region.

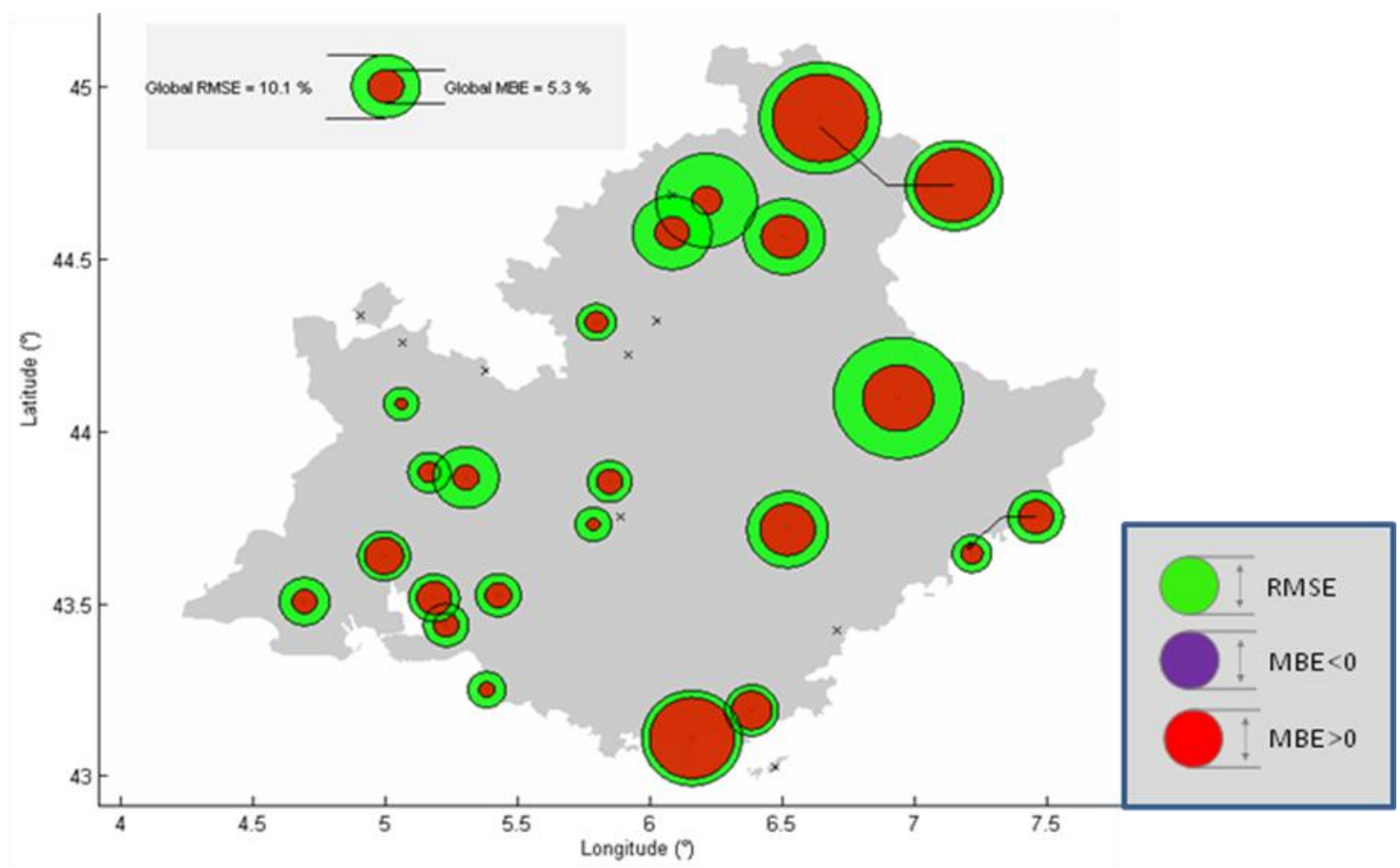

Fig. 6: Graphical representation of the monthly GHI estimation errors between HC3 and the ground station measurements before the calibration of $\mathrm{HC} 3$ and before the correction from orographic effects. When a couple of stations is too close to each other for this representation of errors, they are connected by a line. This is the reason why one station of each couple is represented outside the PACA region. The black crosses represent the MF stations not used for the atlas.

Table 1 gives the summarization of all the statistical results for the comparison between the ground stations and $\mathrm{HC} 3$ before any calibration or correction from orographic effects.

\begin{tabular}{|c|c|c|c|c|c|c|}
\cline { 2 - 7 } \multicolumn{1}{c|}{} & NDATA & MREF & MBE & MAE & RMSE & CC \\
\hline $\begin{array}{c}\text { Monthly sums of GHI } \\
\text { (Ref.: MF stations) }\end{array}$ & 1269 months & $132.2 \mathrm{kWh} / \mathrm{m}^{2}$ & $5.3 \%$ & $7.5 \%$ & $10.1 \%$ & 0.992 \\
\hline
\end{tabular}

Table 1: Results of the statistical analyses of the monthly GHI estimation error between HC3 and the ground station measurements before the calibration of $\mathrm{HC} 3$ and the correction from the orographic effects.

Table 2 gives the results of these statistical analyses between the ground stations and HC 3 after calibration and correction from orographic effects. The statistical comparisons with the MF stations without and with the LOOCV approach and with the RSP stations are corroborating each other. The MBE of the estimation of monthly sums of GHI is less than $1 \%$ and its RMSE is close to $5 \%$ (i.e. $\sim 7 \mathrm{kWh} / \mathrm{m}^{2}$ ). It is important to note that these values are an average over the region. For mountainous areas, the RMSE is around $6 \%$ (with almost no bias) whereas for non mountainous areas, the value is around $3.5 \%$. 


\begin{tabular}{|c|c|c|c|c|c|c|}
\cline { 2 - 6 } \multicolumn{1}{c|}{} & NDATA & MREF & MBE & MAE & RMSE & CC \\
\hline $\begin{array}{c}\text { Monthly sums of GHI } \\
\text { (Ref.: MF stations) }\end{array}$ & 1269 months & $132 \mathrm{kWh} / \mathrm{m}^{2}$ & $-0.2 \%$ & $3.1 \%$ & $4.3 \%$ & 0.996 \\
\hline $\begin{array}{c}\text { Monthly sums of GHI } \\
\text { (LOOCV - Ref.: MF stations) }\end{array}$ & 1267 months & $132 \mathrm{kWh} / \mathrm{m}^{2}$ & $-0.7 \%$ & $4.4 \%$ & $6.2 \%$ & 0.991 \\
\hline $\begin{array}{c}\text { Monthly sums of GHI } \\
\text { (Test: 3 RSP stations) }\end{array}$ & 38 months & $126 \mathrm{kWh} / \mathrm{m}^{2}$ & $0.4 \%$ & $2.5 \%$ & $3.1 \%$ & 0.998 \\
\hline
\end{tabular}

Table 2: Results of the statistical analyses for the uncertainty of the monthly sums of GHI provided by the solar atlas.

Fig. 7 represents graphically these statistical results after calibration and orographic effects correction of $\mathrm{HC} 3$ at all the ground stations locations over the PACA region.

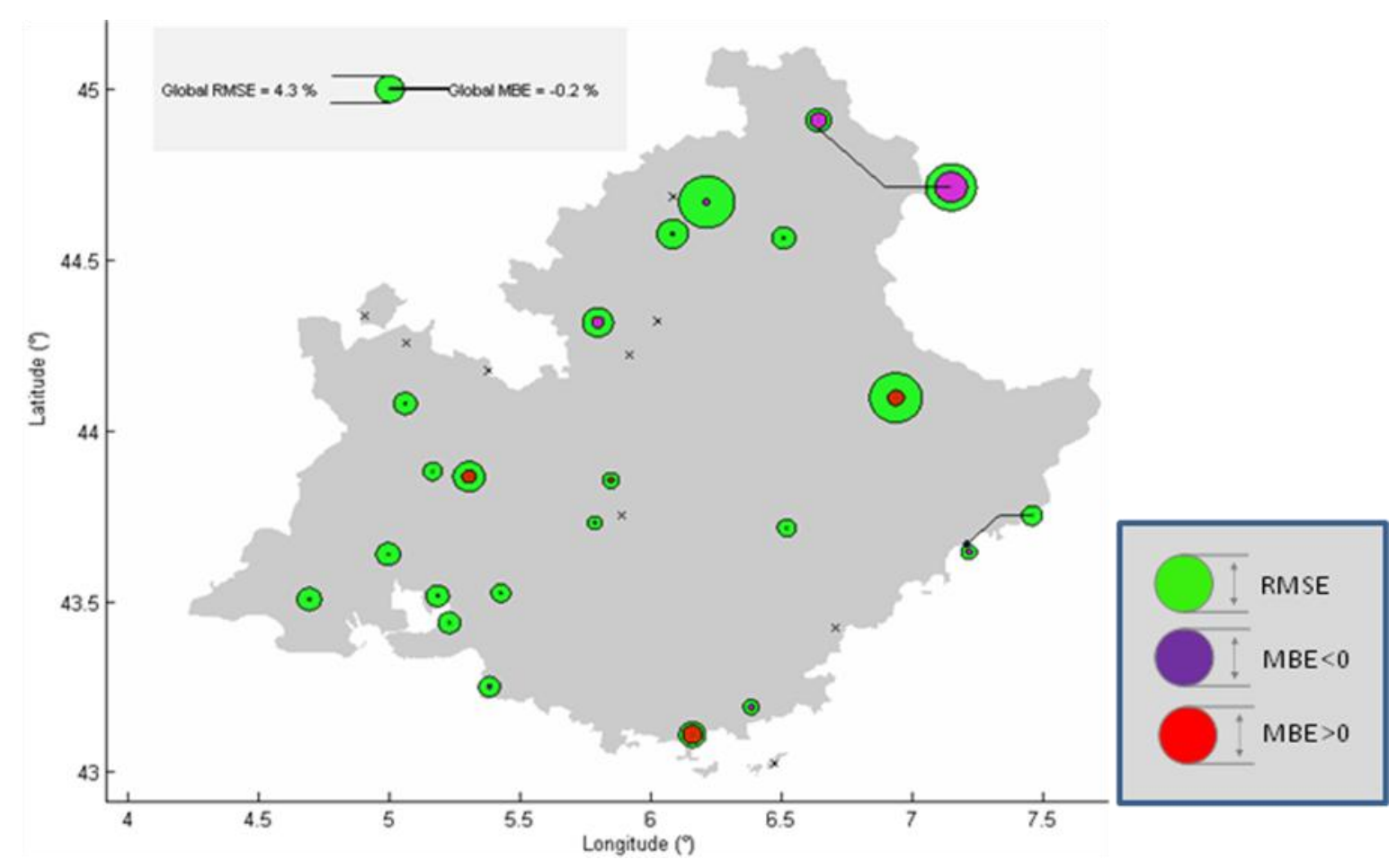

Fig. 7: Graphical representation of the monthly GHI estimation error between the calibrated and corrected (from orographic effects) HC3 and the ground stations measurements. When a couple of stations are too close to each other for this representation of errors, they are connected by a line. This is the reason why one station of each couple is represented outside the PACA region. The black crosses represent the MF stations not used for the atlas.

We have also analyzed the quality of the monthly $\mathrm{HC} 3 \mathrm{BNI}$ values after the calibration and orography corrections. For the estimation of monthly sums of BNI, the statistical analysis was based on the comparisons with the only MF station providing BNI measurements (Carpentras) and the three RSP stations. Table 3 gives the results of this analysis. Although the mean bias error is still lower than $1 \%$, the RMSE for the BNI estimation is around $8 \%$ (i.e. $\sim 12.5 \mathrm{kWh} / \mathrm{m}^{2}$ ) and is greater than for the GHI estimation.

\begin{tabular}{|c|c|c|c|c|c|c|}
\cline { 2 - 7 } \multicolumn{1}{c|}{} & NDATA & MREF & MBE & MAE & RMSE & CC \\
\hline $\begin{array}{c}\text { Monthly sums of DNI } \\
\text { (1 MF stations and 3 RSP stations) }\end{array}$ & 112 months & $156 \mathrm{kWh} / \mathrm{m}^{2}$ & $0.9 \%$ & $6.3 \%$ & $7.9 \%$ & 0.977 \\
\hline
\end{tabular}

Table 3: Results of the statistical analyses for the uncertainty of the monthly sums of DNI provided by the solar atlas. 


\section{Conclusion, dissemination and perspectives}

A new solar atlas over the French region of Provence-Alpes-Côte d'Azur (PACA) has been presented. It is based on the satellite-derived solar database Helioclim-3 (HC3) calibrated with ground stations. The spatial resolution has been increased from $5 \mathrm{~km}$ to $250 \mathrm{~m}$ using the DEM SRTM (Farr et al., 2007). This enhancement has been achieved taking into account the variation of the incident solar irradiation, inside of each of the HC3 pixels, in two ways: considering the fraction of the sky hidden by the orographic horizon as well as the effect of optical path length variation due to terrain elevation.

The solar atlas PACA is freely available at www.atlas-solaire.fr. It provides yearly averaged irradiation maps for the GHI, DHI and BNI solar components, as well as their monthly variation for all the period of HC3 (2004-2010). The availability of this different irradiation information as well as the spatial and temporal resolution of the atlas is suitable as a help in choosing the location, the calculation of profitability or the sizing of photovoltaic or thermodynamic solar power systems.

The regional organizations and councils which funded the project believe that the local atlas represents an efficient promotion tool for alternative electricity generation and for help in decision making. It enables a better prediction to control the introduction of renewable energies in the local grid.

The uncertainty of the atlas has been established by a direct statistical analysis with a set of reference ground stations as well as by cross-validation error estimation. The RMSE of monthly irradiation estimation is about $5 \%$ (i.e. $\sim 7 \mathrm{kWh} / \mathrm{m}^{2}$ ) for the global irradiation on horizontal plane, without significant bias error. The RMSE of monthly direct normal irradiation is about $8 \%$ (i.e. $\sim 12.5 \mathrm{kWh} / \mathrm{m}^{2}$ ).

The developed web map service of the atlas is coherent with the Open Geospatial Consortium (OGC) conventions, and is available at www.webservice-energy.org/mapserv/atlas_paca_v1.0_beta. A nonexhaustive list of clients for visualization and exploitation can be composed of Google Earth (WMS implementation), Web GIS clients (GEO-portal and the GIS of the French department of ecology CARMEN), GIS software (e.g. the freeware Quantum-GIS).

Further actions to disseminate and extend the basis of the current work have already started.

- In the European FP7 funded ENDORSE project (www.endorse-fp7.eu) the PACA Solar Atlas will be improved and disseminated further as a downstream service, paving the way to extend this concept to other regions in Europe. In particular, the atlas will be enriched with more information layers like the minimum/maximum temperatures, the maximum of the monthly wind speed, the distances to the nearest electricity grid line, $\ldots$

- In the German Federal Ministry for Environment, Nature Conservation and Nuclear Safety under the International Climate Initiative funded SolarMedAtlas project (www.solar-med-atlas.com), an atlas covering the countries located on the south of the Mediterranean sea will be made available to facilitate the development of solar energy projects in this region.

The lack of availability of ground station GHI data in some regions is currently an issue to extend this Solar Atlas concept in all the zones with high solar potential. This issue is even more acute for the measure of BNI. To overcome these limitations and lighten the need for ground station calibration, models to obtain irradiation from satellite images need to be improved.

\section{References}

Arlot, S., A. Celisse, 2010. A survey of cross-validation procedures for model selection. Statistics Surveys. 4: 40-79.

Baillargeon, S., 2005. Le krigeage : revue de la théorie et application à l'interpolation spatiale de données de précipitations. Mémoire de M.Sc. de l'Université de Laval. 137 pages.

Dozier, J., J. Frew. 1990. Rapid calculation of terrain parameters for radiation modeling from digital elevation dam. IEEE Transactions on Geoscience and Remote Sensing, 28: 963-969. 
Farr, T. G., et al., 2007. The Shuttle Radar Topography Mission, Rev. Geophys., 45, RG2004, doi:10.1029/2005RG000183.

Geiger, M., L. Diabaté, L. Ménard, L. Wald, 2002. A Web service for controlling the quality of global solar irradiation. Solar Energy, 73, 6, 475-48.

Geuder, N., F. Trieb, C. Schillings, R. Meyer, V. Quaschning, 2003. Comparison of different methods for measuring solar irradiation data. In proceedings of the 3rd International Conference on Experiences with Automatic Weather Stations, 19th-21st of February 2003, Torremolinos, Spain. 9 pages.

Long, C.N., Y. Shi, 2006. The QCRad Value Added Product: Surface Radiation Measurement Quality Control Testing, Including Climatologically Configurable Limits. Atmospheric Radiation Measurement Program Technical Report, ARM TR-074, 69 pages.

Ohmura, A., H. Gilgen, H. Hegner, G. Müller, M. Wild, E. G. Dutton, B. Forgan, C. Fröhlich, R. Philipona, A. Heimo, G. König-Langlo, B. McArthur, R. Pinker, C. H. Whitlock, K. Dehne, 1998. Baseline Surface Radiation Network (BSRN/WCRP): New Precision Radiometry for Climate Research. Bulletin of the American Meteorological Society, 79(10), 2115-2136.

Pavlis, N.K., J. K. Factor, S. A. Holmes, 2006. Terrain-Related Gravimetric Quantities Computed for the Next EGM. In: proceedings of IGFS 2006, Istanbul, Turkey.

Perez, R., P. Ineichen, E.L. Maxwell, R. Seals, A. Zelenka, 1992. Dynamic global to direct irradiance conversion model. ASHRAE Transactions Research Series, 354-369.

Perez, R., P. Ineichen, R. Seals, J. Michalsky, R. Stewart, 1990. Modelling daylight availability and irradiance components. Solar Energy, 44: 271-289.

Rigollier, C., M. Lefèvre, L. Wald, 2004. The method Heliosat-2 for deriving shortwave solar radiation data from satellite images. Solar Energy, 77(2), 159-169.

Ruiz-Arias, J. A., 2009. Modelization of the terrain's morphology influence on the solar radiation field at the Earth's surface. Doctoral thesis. University of Jaén. April 2009. 202 pages.

Ruiz-Arias, J.A., H. Alsamamra, J. Tovar-Pescador, D. Pozo-Vázquez, 2010. Proposal of a regressive model for the hourly diffuse solar radiation under all sky conditions. Energy Conversion and Management, 51: 881893.

The European Solar Radiation Atlas. 2000. Database and exploitation software. Coordinators : K. Scharmer, J. Greif. Les Presses de l'Ecole des Mines de Paris. Vol. 2, 296 pages.

Wahab, A. M., M. El-Metwally, R. Hassan, M. Lefèvre, A. Oumbe, L. Wald, 2008. Assessing surface solar irradiance in Northern Africa desert climate and its long-term variations from Meteosat images. International Journal of Remote Sensing, 31(01), $261-280$.

Wahba G, 1990. Spline models for observational data, In the CBMS-NSF Regional. Conference Series in applied mathematics, Philadelphia, Pennsylvania USA, 59, XII, 169.

Xia, Y., M. Winterhalter, P. Fabian. 2000. Interpolation of Daily Global Solar Radiation with Thin Plate Smoothing Splines. Theory of Applied Climatology, 66: 109-115. 